\title{
Maternal outcomes of magnesium sulphate and diazepam use in women with severe pre-eclampsia and eclampsia in Ethiopia
}

\author{
Gizat M. KASSIE, Dereje NEGUSSIE, Jemal H. AHMED.
}

Received (first version): 13-Dec-2013 Accepted: 5-Apr-2014

\begin{abstract}
${ }^{*}$
Background: Preferred anticonvulsant used to treat and prevent fits in eclampsia currently is magnesium sulphate. Clinical monitoring of tendon reflexes, respiration rate and measuring hourly urine output should be done to ensures safe administration of magnesium sulphate

Objective: This study was conducted to evaluate maternal outcomes of magnesium sulphate and diazepam use in the management of severe pre-eclampsia and eclampsia in Jimma University Specialized Hospital.

Methods: A retrospective hospital based cross-sectional comparative study was conducted using data collection format. Data was collected from the hospital delivery care register and patient chart records of all pregnant women who presented with the diagnosis of severe pre-eclampsia and eclampsia in two years and three months period from January, 2010 to April, 2012. Data analysis was done by SPSS version 16.0. A P-value of $<0.05$ was considered statistically significant in all tests.

Results: A total of 357 patient charts, 217 from magnesium sulphate and 140 from diazepam treated pregnant women group, were reviewed and analyzed. Three pregnant women from the magnesium sulphate treated group and eleven pregnant women from diazepam treated group had at least one convulsion after taking the drug. Greater proportion of patients in the magnesium sulphate treated group had less than four days postpartum stay as compared to the diazepam treated patients $(82.3 \%$ versus $66.2 \%$ ). Seizure occurrence, duration of postpartum hospital stays and birth outcome had a statistically significant association with the type of anticonvulsant used.

Conclusions: Magnesium sulphate is more effective than diazepam in the management of severe pre-eclamptic and eclamptic pregnant women in terms of seizure prevention, shortening postpartum hospital stay and reducing maternal morbidities.
\end{abstract}

Keywords: Magnesium Sulfate; Diazepam; Hypertension, Pregnancy-Induced; Seizures; Pregnant Women Comparative Effectiveness Research; Ethiopia

\footnotetext{
Gizat Molla KASSIE. Clinical Pharmacist and Lecturer Department of Pharmacy, College of Public Health and Medical Sciences, Jimma University. Jimma (Ethiopia). geez99@gmail.com

Dereje NEGUSSIE. Consultant Obstetrician and

Gynecologist, Department of Gynecology and obstetrics, College of Public Health and Medical Science, Jimma University. Jimma (Ethiopia). negussiedereje@yahoo.co.uk Jemal Hussien AHMED. Assistant professor of Medicinal Chemistry, Department of Pharmacy, College of Public Health and Medical Sciences, Jimma University. Jimma (Ethiopia).jemms@rediffmail.com
}

\section{INTRODUCTION}

Pre-eclampsia is a condition unique to pregnancy that is characterized by new onset of hypertension and proteinuria. $^{1}$ Pre-eclampsia is a relatively common complication of pregnancy, and can occur at any time during the second half of pregnancy or in the first few weeks after delivery. For many women who have pre-eclampsia the maternal outcome is good, but severe disease can lead to death or serious problems for the woman. Severe pre-eclampsia is associated with multiple organ system involvement including renal failure, cerebral hemorrhage and edema, hepatic failure and rupture, and thrombocytopenia in addition to pre-eclampsia. ${ }^{2}$

Pre-eclampsia and eclampsia are not distinct disorders but the manifestations of the same condition. In pre-eclampsia, hypertension and proteinuria are present, and when convulsions occur after other causes of convulsion are excluded in addition to these signs, the condition is referred to as eclampsia. ${ }^{1}$ Eclampsia is a serious complication increasing the risk of maternal morbidity and mortality.

Current strategies for prevention of pre-eclampsia can be broadly classified as antenatal surveillance, modification of lifestyle, nutritional supplementation, and pharmacological therapy. The only definitive treatment for pre-eclampsia or eclampsia is to end the pregnancy. The aim of interventions for women with eclampsia is to prevent further seizures, to minimize and treat any complications and, if not delivered, to optimize the timing of birth for the baby. Currently, standard care for women with severe pre-eclampsia/eclampsia is to use an anticonvulsant drug to control the immediate fit, and to continue maintenance treatment to prevent further seizures. ${ }^{4}$

In Ethiopia, magnesium sulphate is introduced as an anticonvulsant for treatment of severe preeclampsia and eclampsia. Diazepam is still in use as an alternative in the absence of magnesium sulphate. ${ }^{5,6}$

Although there are many studies that report the effectiveness of magnesium sulphate in treating and preventing eclampsia, questions still exist as to its safety. ${ }^{7}$ According to the Magpie Trial Collaborative Group, $24 \%$ of women treated with magnesium sulphate reported side-effects and $16 \%$ of them stopped treatment early. ${ }^{8}$ Another retrospective study in Nigeria reported that, approximately nine percent of those treated with magnesium sulphate 
develop toxicity [ $85.5 \%$ renal and $12 \%$ respiratory]. ${ }^{9}$ Thirty six percent of eclamptic pregnant women treated with magnesium sulphate, in Tanzania, needed extra-care and prolonged stay in intensive care unit (ICU). ${ }^{7}$

Proper administration of magnesium sulphate (MgSO4) is again a problem in many low resource settings like ours where electric infusion pumps are not available or feasible for intravenous administration. The intramuscular dosing regimen requires repeated painful injections which may be a barrier to optimal utilization. ${ }^{2}$

The Ethiopian Society of Obstetricians and Gynecologists has done a project from April 2009 to July 2011 to contribute towards the reduction of maternal mortality by introducing magnesium sulphate in all public hospitals in Ethiopia. The activities done by the society were an advocacy on magnesium sulphate, training of Obstetricians and Gynecologists, general Practitioners, health Officers \& midwifes, data collection in 24 hospitals selected for audit and distribution of magnesium sulphate. ${ }^{10}$

However, there are no studies done to assess the impact of the drug on maternal outcomes and compare it with diazepam after its introduction in public hospitals in Ethiopia in general and in Jimma University Specialized Hospital in particular. Therefore, this study was done to evaluate the maternal outcome of magnesium sulphate and diazepam use in the management of severe preeclampsia and eclampsia in Jimma University Specialized Hospital (JUSH).

\section{METHODS}

This hospital based retrospective cross-sectional comparative study was conducted from February 13, 2012 to April 15, 2012 in JUSH, which is located in Jimma town. The hospital is one of the oldest public hospitals in the country and provides almost all major types of medical services such as Clinical services including Delivery and maternal and child health Services for approximately 9000 inpatient and 80000 outpatient attendants a year from the catchment population of about 15 million in southwest Ethiopia. ${ }^{11} \mathrm{JUSH}$ is the only teaching and referral hospital in the southwestern part of the country with a total bed capacity of 450 of which 47 are found in the maternity ward. ${ }^{11}$ The labor and maternity wards are run by midwives, medical and health officer interns, resident physicians of obstetrics and gynecology, and senior physicians of obstetrics and gynecology. JUSH has an ICU of eight beds with two anesthesiologists and various groups of residents and nurses working 24 hours.

All pregnant women who were admitted to JUSH Maternity Ward in the two years and three months period i.e. from January 03, 2010 - April 02, 2012 were considered as the source population. Women who were diagnosed with severe pre-eclampsia or eclampsia and for which either magnesium sulphate or diazepam was administered for prophylaxis or treatment of seizures were included in the study. Pregnant women referred from other health institutions taking any anticonvulsant before reaching the hospital were not included in the study. Data was collected using a structured data collection format which contained maternal details (Age of the mother, Gravidity, History of previous pre-eclampsia/eclampsia, Previous history of hypertension), antenatal care follow up status, diagnosis, type of anticonvulsants used, major maternal morbidities, side effects encountered, postpartum duration of stay, admission status of the mother to the intensive care unit other relevant information. The data collection format was pretested on 19 patient records (5\%) in order to check any inconsistencies and necessary adjustments were made before the actual period of the study.

Data was collected by a medical intern and a postgraduate clinical pharmacy student of Jimma University after orientation and training for three days. Data was obtained from the hospital delivery care register, Log Book and patient chart review. At the end of each day, the completeness and consistency of data collected was checked by the principal investigator. Then, the collected data was organized, cleaned, coded and analyzed by SPSS version 16.0 for windows.

Descriptive analyses were used to describe the socio-demographic details of pregnant women such as age, diagnosis, type of anticonvulsant used, gravidity, antenatal care follow up status and previous history of hypertension, types of major maternal morbidities and types of side effects of magnesium sulphate. Chi-square test was used to determine the presence of association between the type of anticonvulsant used and the outcome variables. A binary logistic regression was done to assess the presence and degree of association between type of anticonvulsant used and some maternal outcome variables using odds ratio with $95 \%$ confidence interval. The Kruskal Wallis non parametric test was employed to test the association of type of anticonvulsant used with postpartum hospital stay. A P-value of $<0.05$ was considered statistically significant for all the tests.

Ethical clearance was secured from the college of Public Health and Medical sciences ethical review board (Ref. No RPGC/114/2012), Jimma University before data collection. Concerned bodies at all levels, including the hospital clinical director and department of obstetrics and gynecology, were communicated and approval was granted. Any personally identifiable information (e.g., name, address) was not recorded. Patient cards were returned to the card room after data collection.

\section{RESULTS}

A total of 357 patient cards were reviewed during the study period and included in the analysis (card retrieval rate of $84.0 \%$ ). The median age of pregnant women included in the study was 23 years with a range of 18 years. One hundred ninety two $(53.8 \%)$ of them were in the age group $<24$ years. Two hundred four $(57.1 \%)$ of the pregnant women were primigravida and two hundred seventy nine $(78.2 \%, n=357)$ of them had antenatal care follow up during the index pregnancy. One hundred twenty 


\begin{tabular}{|c|c|c|}
\hline Maternal characteristics & $\mathrm{N}$ & $\%$ \\
\hline \multicolumn{3}{|l|}{ Age of the mother (in years) } \\
\hline$<24$ & 192 & 53.8 \\
\hline $2 \overline{5}-34$ & 151 & 42.3 \\
\hline$\geq 35$ & 14 & 3.9 \\
\hline \multicolumn{3}{|l|}{ Gravidity } \\
\hline Primigravida & 204 & 57.1 \\
\hline Multigravida & 153 & 42.9 \\
\hline \multicolumn{3}{|l|}{ Antenatal care follow up status } \\
\hline Yes & 279 & 78.2 \\
\hline No & 78 & 21.8 \\
\hline \multicolumn{3}{|l|}{ Diagnosis } \\
\hline Severe Preeclampsia & 231 & 64.7 \\
\hline Eclampsia & 126 & 35.3 \\
\hline \multicolumn{3}{|l|}{ Previous history of hypertension } \\
\hline Yes & 22 & 6.2 \\
\hline No & 335 & 93.8 \\
\hline \multicolumn{3}{|l|}{ Type of anticonvulsant used } \\
\hline Magnesium sulphate & 217 & 60.8 \\
\hline Diazepam & 140 & 39.2 \\
\hline
\end{tabular}

six $(35.3 \%)$ and $231(64.7 \%)$ pregnant women were diagnosed with eclampsia and severe preeclampsia respectively. Most of the pregnant women $(93.8 \%)$ had no previous history of hypertension. Magnesium sulphate has been used as anticonvulsant for $217(60.8 \%)$ patients (Table 1).

A total of 14 pregnant women $(3.9 \%)$ had at least one convulsion after receiving magnesium sulphate (3 pregnant women) or diazepam (11 pregnant women). A statistically significant association was found between seizure occurrence and type of anticonvulsant used $(P=0.004)$. Among severe preeclamptic pregnant women, one from magnesium sulphate and three from the diazepam treated groups had convulsions after starting of magnesium sulphate and diazepam respectively i.e. only a single severe pre-eclamptic mother has progressed to eclampsia in the magnesium sulphate group as compared to three pregnant women in the diazepam treated group though it failed to show a significant difference. On the other hand, only two pregnant women had recurrence of seizure in the magnesium sulphate treated group as compared to eight pregnant women in the diazepam treated group among eclamptic pregnant women. A statistically significant association was found between seizure recurrence and type of anticonvulsant used in eclamptic pregnant women $(\mathrm{P}=0.038)$.

In addition, out of all pregnant women who received anticonvulsant medication, $51 \quad(14.3 \%)$ have

\begin{tabular}{|l|c|}
\hline \multicolumn{2}{|l|}{$\begin{array}{l}\text { Table 3. Types of major maternal morbidities among } \\
\text { severe pre-eclamptic and eclamptic pregnant women. }\end{array}$} \\
\hline \multicolumn{1}{|c|}{ Morbidity } & $\%$ \\
\hline Aspiration pneumonia & $36.2 \%$ \\
\hline HEELP syndrome & $34.8 \%$ \\
\hline Respiratory depresion & $17.4 \%$ \\
\hline Renal failure & $8.7 \%$ \\
\hline DIC & $1.4 \%$ \\
\hline Stroke & $1.4 \%$ \\
\hline
\end{tabular}

developed major maternal morbidities, 16 pregnant women from magnesium sulphate $(7.4 \%)$ and 35 pregnant women (25\%) from diazepam treated groups. The association between occurrence of major maternal morbidity and type of anticonvulsant used was statistically significant $(P<0.001)$. Lower proportion of pregnant women had developed major morbidities in those treated with magnesium sulphate than diazepam $(6.9 \%$ versus $15.0 \%$ in sever pre-eclampsia and 7 pregnant women versus 26 pregnant women in eclampsia) both in severe pre-eclamptic and eclamptic pregnant women and shows a statistically significant association $(p=0.001$ $\& p<0.001$ ) (Table 2). Table 3 presents the types of major maternal morbidities identified.

A total of six deaths, two from magnesium sulphate and four from diazepam group were recorded. All of the deaths were from eclamptic pregnant women.

During the two years and three months period, there were 20 admissions of patients with severe preeclampsia and eclampsia to the ICU. Although more number of pregnant women $(8.6 \%)$ who received diazepam (12 pregnant women) were admitted to the ICU as compared to those who received magnesium sulphate (8 pregnant women), there was no statistically significant association between type of anticonvulsant used and admission to ICU $(P=0.060)$. The association has also failed to be significant when it is analyzed separately for sever pre-eclamptic and eclamptic pregnant women $(\mathrm{P}=$ $0.555 \& 0.050)$

Moreover, Large proportion of pregnant women 64 $(91.4 \%, n=70)$ encountered one or more side effects to magnesium sulphate therapy. Injection site problems $(88.6 \%, n=70)$ and flushing $(67.1 \%$, $\mathrm{n}=70$ ) were the most commonly encountered side effects. There was no mother with respiratory depression. Even though there was no treatment discontinuation because of side effects, there was one missing of dose. Regarding clinical monitoring, all of the pregnant women who received magnesium sulphate were monitored. Respiratory rate, deep tendon reflex and urine output were monitored in

\begin{tabular}{|c|c|c|c|c|}
\hline \multirow{2}{*}{ Diagnosis } & \multicolumn{3}{|c|}{ Type of anticonvulsant used. N (\%) } & \multirow{2}{*}{ p-value } \\
\hline & Magnesium sulphate & Diazepam & Total & \\
\hline $\begin{array}{r}\text { Severe pre-eclampsia } \\
\text { MM Yes } \\
\text { MM No }\end{array}$ & $\begin{array}{c}15(6.9) \\
137(63.1)\end{array}$ & $\begin{array}{l}21(15.0) \\
58(41.4)\end{array}$ & $\begin{array}{c}36(15.6) \\
195(84.4)\end{array}$ & 0.001 \\
\hline $\begin{array}{r}\text { MM Yes } \\
\text { MM No }\end{array}$ & $\begin{array}{c}7(-) \\
58(26.8)\end{array}$ & $\begin{array}{l}26(18.6) \\
35(25.0)\end{array}$ & $\begin{array}{l}33(26.2) \\
93(73.8)\end{array}$ & 0.000 \\
\hline $\begin{array}{c}\text { MM Yes } \\
\text { MM No }\end{array}$ & $\begin{array}{c}16(7.4) \\
201(92.6)\end{array}$ & $\begin{array}{c}35(25.0) \\
105(75.0)\end{array}$ & $\begin{array}{c}51(14.3) \\
306(85.7)\end{array}$ & 0.000 \\
\hline
\end{tabular}




\begin{tabular}{|c|c|c|}
\hline Variable & $\mathrm{N}$ & $\%$ \\
\hline \multicolumn{3}{|l|}{ Type of side effect } \\
\hline Flushing & 47 & 67.1 \\
\hline Nausea and/or vomiting & 27 & 38.6 \\
\hline Injection site problem & 62 & 88.6 \\
\hline \multicolumn{3}{|l|}{ Monitoring parameter } \\
\hline Respiratory rate & 70 & 100 \\
\hline Deep tendon reflex & 69 & 98.6 \\
\hline Urine output & 67 & 95.7 \\
\hline
\end{tabular}

100, 98.6 and $95.7 \%$ of pregnant women respectively (Table 4).

Regarding the mean length of postpartum hospital stay, pregnant women treated with magnesium sulphate have stayed for $2.59(\mathrm{SD}=1.96)$ days, while those treated with diazepam group had stayed for $3.79(S D=2.58)$ days. Greater proportion of patients in the magnesium sulphate treated group had less than four days postpartum stay as compared to the diazepam treated patients $(83.3 \%$, $\mathrm{n}=215$ versus $66.2 \%, \mathrm{n}=136$ ). The length of maternal postpartum stay in the hospital had a statistically significant association with the type of anticonvulsant used in severe pre-eclampsia $(P=0.016)$ though not in eclampsia $(P=0.076)$. But, Over all, it showed statistically significant associated with the type of anticonvulsant used $(P=0.000)$ (Table 5).

Binary logistic regression analysis indicated that the likelihood of seizure occurrence and major maternal morbidity after taking anticonvulsant in the magnesium sulphate treated pregnant women was 0.164 and 0.223 times their counterparts in the diazepam treated group respectively (Table 6).

\section{DISCUSSION}

Most of the pregnant women included in this study were primigravida (57.1\%) and had antenatal care follow up during the index pregnancy $(78.2 \%)$. The antenatal care follow up is comparable with the study done in Jimma University Specialized Hospital by Zenebe et al. (2009-2010) in which it was $74.7 \% .^{12}$ The slight increase in the rate of antenatal care follow up in the current study could be because of the awareness created by the current governmental interventions and improvement in antenatal care coverage. Most of the cases of this study were pregnant women with severe preeclampsia $(64.7 \%)$ which was also reported as the most common hypertensive disorder of pregnancy in the previous study. ${ }^{12}$

The principal goals of treatment in eclampsia are stopping the convulsions and preventing further fits which are associated with reduction in adverse outcome. This has been reported to depend on the type of anticonvulsant used. In this study, pregnant women who have taken magnesium sulphate had a lower rate of seizure occurrence as compared with pregnant women who have taken diazepam as anticonvulsant $\{(1.4 \%$ versus $7.9 \%) \quad(O R=0.164$, $95 \% \mathrm{Cl} 0.045$ to 0.600$)\}$. Other studies have forwarded similar findings for treatment of eclamptic seizures and also for prevention of recurrence of seizures in eclampsia and severe preeclampsia. ${ }^{13,14}$ It has also been revealed, in a typical systematic quantitative review and analysis, that magnesium sulphate was more effective than other interventions in preventing recurrent seizures in eclampsia and in preventing the first seizure in pre-eclampsia. ${ }^{15}$ Another meta-analysis by Duley et al. has reported a substantial reduction in the risk recurrence of further fits (RR=0.44, $95 \% \mathrm{Cl} 0.34$ to 0.57 ) in eclamptic pregnant women. ${ }^{16}$ According to Getaneh in teaching hospitals in Addis Ababa, there were no woman with severe pre-eclampsia convulsed after initiation of magnesium sulphate, while four of the eclamptic pregnant women had recurrence of seizures. ${ }^{17}$ There was also only one severe preeclamptic mother who progressed to eclamptic after initiation of magnesium sulphate in the current study. The smaller number of eclamptic pregnant women who had seizure recurrence in this study, as compared to the study in Addis Ababa, might be associated with the training of health professionals on the use of magnesium sulphate so that physicians became more familiar with the drug.

The findings in the current study has shown that the use of magnesium sulphate as anticonvulsant was better than diazepam in reducing major morbidities in pregnant women with severe pre-eclampsia and eclampsia (major morbidity is observed in $7.4 \%$ and $25.0 \%$ of magnesium sulphate and diazepam treated pregnant women respectively) ( $O R=0.223$, $95 \% \mathrm{Cl} 0.127$ to 0.392 ) and only two of the six maternal deaths were from the magnesium sulphate

\begin{tabular}{|c|c|c|c|c|}
\hline \multirow[b]{2}{*}{$\begin{array}{l}\text { Postpartum stay in the hospital } \\
\text { (days) }\end{array}$} & \multicolumn{3}{|c|}{ Type of anticonvulsant used. N (\%) } & \multirow[b]{2}{*}{$\mathrm{p}$-value } \\
\hline & $\begin{array}{l}\text { Magnesium sulphate } \\
(n=215)\end{array}$ & $\begin{array}{l}\text { Diazepam } \\
(n=136)\end{array}$ & Total & \\
\hline Severe pre-eclampsia & $\begin{array}{c}130(85.5) \\
17(11.2) \\
5(-)\end{array}$ & $\begin{array}{c}55(69.6) \\
18(22.8) \\
6(-)\end{array}$ & $\begin{array}{c}185(80.1) \\
35(15.2) \\
11(4.8)\end{array}$ & 0.016 \\
\hline Eclampsia & $\begin{array}{c}49(77.8) \\
12(19.0) \\
2(-)\end{array}$ & $\begin{array}{c}35(61.4) \\
15(26.3) \\
7(-)\end{array}$ & $\begin{array}{c}84(70.0) \\
27(22.5) \\
9(-)\end{array}$ & 0.076 \\
\hline $\begin{array}{r}<4 \\
4-8 \\
>8 \\
\end{array}$ & $\begin{array}{c}179(83.3) \\
29(13.4) \\
7(-)\end{array}$ & $\begin{array}{c}90(66.2) \\
33(9.6) \\
13(24.3) \\
\end{array}$ & $\begin{array}{c}269(76.6) \\
62(17.7) \\
20(5.7) \\
\end{array}$ & 0.000 \\
\hline
\end{tabular}




\begin{tabular}{|c|c|c|c|c|}
\hline $\begin{array}{l}\text { Table 6. Binary logistic regression of some outcome variables with type of } \\
\text { anticonvulsant used, JUSH, January } 2010-\text { April 2012. }\end{array}$ & $\begin{array}{l}\text { OR } \\
\text { Type of anticonvulsant }\end{array}$ & $\begin{array}{c}\text { Outcome } \\
\text { variable }\end{array}$ & p-value & OR \\
\hline Seizure occurrence & & & & \\
\hline Magnesium sulphate & 3 & 0.006 & 0.164 & $0.045-0.600$ \\
\hline Diazepam & 11 & & 1 & Reference \\
\hline Maternal morbidity & & & & \\
\hline Magnesium sulphate & 16 & 0.000 & 0.223 & $0.127-0.392$ \\
\hline Diazepam & 35 & & 1 & Reference \\
\hline
\end{tabular}

group though the difference is not statistically significant. Duley et al. found that magnesium sulphate was associated with a reduction in maternal death when compared to diazepam [relative risk $(\mathrm{RR})=0.59,95 \%$ confidence interval (CI) 0.37 to 0.94$].{ }^{16}$ According to Khan, magnesium sulphate was the better anticonvulsant than diazepam infusion in terms of total morbidity and maternal deaths (Null versus $5 \%$ ). ${ }^{18}$ A Randomized Double Blind Trial of Magnesium Sulphate and Diazepam in Lagos, Nigeria also showed that the use of magnesium sulphate was found to be significantly associated with less serious morbidity in comparison to diazepam use. ${ }^{19}$ A similar significant reduction in maternal deaths was reported in Tanzania. ${ }^{7}$

Concerning maternal admission to the intensive care unit (ICU), this study failed to show significance difference between the diazepam treated and magnesium sulphate treated pregnant women though a high proportion of ICU admitted pregnant women were from the diazepam treated group. This result agrees with three trials published by The Cochrane Library in 2010 which reports that admission to an intensive care unit had no significant difference between the two groups $(\mathrm{RR}=0.80,95 \% \mathrm{Cl} 0.59$ to 1.07$) .{ }^{20}$ In this study, admission to ICU in the magnesium sulphate group is $3.7 \%$ which is comparable with the result in the Magpie trial $(2 \%){ }^{8}$ The $12(8.6 \%)$ admissions in the diazepam treated group is similar with the study done in Jimma University specialized hospital (there were 14 admissions in a year) during which diazepam was the main anticonvulsant in the hospital. $^{12}$

According to a recent study in New Delhi (2012) the use of magnesium sulphate was associated with a reduction in admission to an intensive care unit $(\mathrm{RR}=0.67,95 \% \mathrm{Cl} 0.50-0.89) .{ }^{21}$ But a study in Tanzania reported that $36 \%$ of eclamptic pregnant women treated with magnesium sulphate needed extra care in $\mathrm{ICU}^{7}$ The lower rate of admission in this study $(5.6 \%)$ could be explained by the limited number of beds in this Hospital's ICU so that all pregnant women who deserve admission might not be admitted.

Regarding side effects of magnesium sulphate, it has been found that problems at intramuscular injection site are the most commonly reported side effects $(88.6 \%)$ followed by flushing $(67.1 \%)$ and nausea and/or vomiting $(38.6 \%)$. Similar findings were obtained from studies conducted elsewhere. ${ }^{16,22-24}$ According to The Magpie Trial intramuscular injection site problems account only $12 \%$ of magnesium sulphate received pregnant women. ${ }^{8}$ In another study by Ritu Sharma et al.
(2012), only a quarter of women who received magnesium sulphate had such side-effects and by far the most common side-effect was flushing. ${ }^{21}$ In the current study, the injection site problems are higher than the above two studies. This might be explained by the fact that the pregnant women in our setting are thinner and less muscular.

There was no any report of respiratory depression and discontinuation of the drug because of side/adverse effects during the study period. This result is consistent with a study done on Magnesium sulphate Versus Diazepam Infusion in Eclampsia in Annals of King Edward Medical University in 2009, But the finding contradicts with a retrospective study in Nigeria that shows a report of magnesium sulphate toxicity especially acute renal and respiratory depression in $9 \%$ of patients. ${ }^{9,18}$ The absence of severe magnesium sulphate toxicities in this study could be possibly because of frequent clinical monitoring by different students as JUSH is a teaching hospital.

Duration of hospital stay in eclampsia and severe preeclampsia indicates the morbidity associated with these diseases and has an implication on the efficacy and safety of treatment options. In this study there was a significant difference in the length of postpartum hospital stay in pregnant women treated with magnesium sulphate as compared to diazepam treated ones. The advantage of magnesium sulphate over diazepam in reducing hospital stay has also been revealed by other studies. ${ }^{18,20,25}$

This study has shown that mean duration of postpartum stay in the hospital in pregnant women treated with magnesium sulphate is shorter as compared to the diazepam group [2.59 $(\mathrm{SD}=1.96)$ days versus $3.79 \quad(S D=2.58)$ days]. Greater proportion of patients in the magnesium sulphate treated group had less than four days postpartum hospital stay as compared to the diazepam treated pregnant women (82.3\% versus $66.2 \%)$. According to a study done in Nigeria after introduction of magnesium sulphate (2011), Longer hospital stay was significantly lower among women who received magnesium sulphate $[\mathrm{OR}=0.32(95 \% \mathrm{Cl} 0.11,0.93)]$. In the study, out of the 36 prolonged hospital stays $11.7 \%$ women were in the magnesium sulphate group and $35.1 \%$ were in the diazepam group. ${ }^{25}$ Another study in New Delhi India (2012) the mean duration of hospital stay in magnesium sulphate treated pregnant women was $4.28(\mathrm{SD}=2.11)$ days and majority $(68 \%)$ of patients had less than 4 days duration. ${ }^{21}$ In the magnesium sulphate treated group, the result in the current study may seem deviated from the previous literature (mean postpartum hospital stay is $2.59(S D=1.96)$ days 
and $82.3 \%$ stayed less than four days).This difference could be because this study compares the postpartum hospital stay where as the previous one calculated the whole duration of stay in the hospital.

\section{Limitations of the study}

The main limitation of this study was being retrospective and its dependence on patients' records. Because of this it was not possible to include the actual drug administration issues. Some patient cards did not contain all necessary information that affected the quality of the study. We has also assumed that patients' management (dose, frequency of administration, etc.) in either group was strictly in line with the hospital's protocol as we were unable to check it retrospectively. Further controlled and prospective studies are recommended to be conducted to evaluate administration of magnesium sulphate and toxicities associated with its use.

\section{CONCLUSIONS}

Pregnant women treated with magnesium sulphate had a lower rate of seizure recurrence in eclamptic pregnant women, shorter postpartum duration of stay in the hospital in severe pre-eclamptic pregnant women and reduced rate of major maternal morbidity in both severe pre-eclamptic and eclamptic pregnant women than those treated with diazepam. The study has also pointed out that injection site problems were the most common side effects of magnesium sulphate therapy followed by flushing and nausea and/or vomiting.

Therefore, concerned bodies are recommended to promote the accessibility and wider use of magnesium sulphate and consider for its inclusion to the list of essential medicines for Ethiopia. Physicians, Nurses and other care givers should take care of missing of doses because of side effects and patients receiving magnesium sulphate should be informed about the side effects of the drug.

\section{ACKNOWLEDGEMENT}

First of all we would like to thank the clients whose records were reviewed. We also acknowledge Jimma University for financing the study. Last but not least we would like to thank the staffs in the department of gynecology and obstetrics, Jimma University and the staffs of the card room of Jimma University Specialized Hospital for retrieving patient cards and their cooperation during the conduction of the study.

\section{CONFLICT OF INTEREST}

None declared.

\section{RESULTADOS MATERNOS DEL USO DE SULFATO DE MAGNESIO Y DIAZEPAM EN MUJERES CON PRE-ECLAMPSIA GRAVE EN ETIOPIA}

\section{RESUMEN}

Antecedentes: El anticonvulsivante preferido para tratar y prevenir ataques en eclampsia es actualmente el sulfato de magnesio. Para garantizar una administración segura del sulfato de magnesio debería realizarse una monitorización clínica de los reflejos tendinales, velocidad de respiración y producción horaria de orina. Objetivo: Este estudio se realizó para evaluar los resultados maternos del uso de sulfato de magnesio y diazepam en el manejo de la pre-eclampsia y eclampsia graves en el Hospital especializado de la Universidad de Jimma.

Métodos: Se realizó un estudio transversal retrospectivo mediante recogida de datos. Los datos se recogieron del registro de cuidados prestados en el hospital y de las historias clínicas de todas las embarazadas que presentaron diagnóstico de pre-eclampsia o eclampsia grave en los dos años y tres meses entre enero 2010 y abril 2012. El análisis se realizó con un SPSS versión 16.0. Se consideró significativo para todas las pruebas un $\mathrm{p}<0,05$.

Resultados: Se revisaron y analizaron un total de 357 historias clínicas de 217 pacientes tratados con sulfato de magnesio y 140 con diazepam. Tres embarazadas tratadas con sulfato de magnesio y 11 tratadas con diazepam habían tenido, al menos, una convulsión después de tomar el medicamento. La mayor proporción de pacientes tratadas con sulfato de magnesio tuvo menos de 4 días de estancia post-parto comparadas con las tratadas con diazepam ( $82,3 \%$ versus $66,2 \%)$. $\mathrm{La}$ aparición de convulsiones, la estancia hospitalaria postparto y los resultados del parto tuvieron asociación estadísticamente significativa con el tipo de anticonvulsivante utilizado.

Conclusiones: El sulfato de magnesio es más efectivo que el diazepam en el manejo de pre-eclampsia y eclampsia graves en términos de prevención de convulsiones, reducción de la estancia hospitalaria postparto y reducción de las morbilidades maternas.

Palabras clave: Sulfato de Magnesio; Diazepam; Hipertensión Inducida en el Embarazo; Convulsiones; Mujeres Embarazadas; Investigación Comparativa sobre la Efectividad; Etiopia

1. Mizutani $\mathrm{S}$, Wright $\mathrm{J}$, Kobayashi $\mathrm{H}$. A new approach regarding the treatment of preeclampsia and preterm labor. Life Sci. 2011;88(1-2):17-23. doi: 10.1016/j.lfs.2010.10.013

2. Mundle S, Regi A, Easterling T, Bivas Biswas B, Bracken H, Khedekar V, Shekhavat DR, Durocher J, Winikoff B. Treatment approaches for preeclampsia in low-resource settings: A randomized trial of the Springfusor pump for delivery of magnesium sulfate. Pregnancy Hyperten. 2012;2(1):32-38. doi:10.1016/j.preghy.2011.09.002

3. Gracia VD. Maternal deaths due to eclampsia and HELLP syndrome. Int J Gynaecol Obstet. 2009;104(2):90-94. doi: 10.1016/j.ijgo.2008.09.014

4. Duley L, Gulmezoglu A. Magnesium sulphate versus lytic cocktail for eclampsia. Cochrane Database Syst Rev. 2001;(1):CD002960. 
5. Drug Aministration and Control Authority E. Standard treatment guidelines for zonal hospitals. Obstetrics and gynecological conditions. Addis Ababa 2010. p. 265-266.

6. Ministry of Health FDRE. Management Protocol on Selected Obstetrics Topics. Addis Ababa 2010. p. 181-182.

7. Muganyizi $P$, Shagdara M. Predictors of extra care among magnesium sulphate treated eclamptic patients at Muhimbili National Hospital, Tanzania. BMC Pregnancy Childbirth. 2011;11:41. doi: 10.1186/1471-2393-11-41

8. Altman D, Carroli G, Duley L, Farrell B, Moodley J, Neilson J, Smith D; Magpie Trial Collaboration Group. Do women with pre-eclampsia, and their babies, benefit from magnesium sulphate? The Magpie Trial: a randomised placebo controlled trial. Lancet. 2002;359(9321):1877-1890.

9. Tukur J, Muhammad Z. Management of eclampsia at AKTH: before and after magnesium sulphate. Niger J Med. 2010;19(1):104-107.

10. ESOG. Magnesium Sulphate use for prevention of Preeclampsia and Eclampsia related mortality in Ethiopia 2011; Available from: http://www.esog.org.et/Projects.htm (accessed 2012 February 3).

11. Office JUER. Jimma University Specialized Hospital and Existing medical services 2012. Available from: http://www.ju.edu.et/jimma-university-specialized-hospital-jush (accessed 2012 February 3).

12. Wolde Z, Segni H, Woldie M. hypertensive disorders of pregnancy in Jimma University Specialized Hospital. Ethiop J Health Sci. 2011;21(3):147-154.

13. Which anticonvulsant for women with eclampsia? Evidence from the collaborative eclampsia trial. Lancet. 1995;345(8963):1455-63.

14. Chaudhary P. Eclampsia: before and after magnesium sulphate. JNMA J Nepal Med Assoc. 2005;44(160):124-128.

15. Tannirandorn $Y$. Is magnesium sulfate for prevention or only therapeutic in preeclampsia. J Med Assoc Thai. 2005 Jul;88(7):1003-1010.

16. Duley L, Gulmezoglu AM, Henderson-Smart DJ, Chou D. Magnesium sulphate and other anticonvulsants for women with pre-eclampsia. Cochrane Database Syst Rev. 2010;(11):CD000025. doi: 10.1002/14651858.CD000025.pub2

17. Getaneh W, Kumbi S. Use of magnesium sulfate in pre-eclampsia and eclampsia in teaching hospitals in Addis Ababa: a practice audit. Ethiop Med J. 2010;48(2):157-164.

18. Ikramullah K, Ambreen, Humera. Magnesium Sulfate Versus Diazepam Infusion in Eclampsia. Annals of King Edward Medical University. 2009;15(3):149-151. Available at http://www.annalskemu.org/journal/index.php/annals/article/viewArticle/84

19. Ola RE, Odeneye O, Abudu OO. Eclampsia: A Randomized Double Blind Trial of Magnesium Sulphate and Diazepam in Lagos, Nigeria. Trop J Obstet Gynaecol. 2005; 21(2):143-147.

20. Duley L, Henderson-Smart DJ, Walker GJ, Chou D. Magnesium sulphate versus diazepam for eclampsia (Review). Cochrane Database Syst Rev. 2010;(12):CD000127. doi: 10.1002/14651858.CD000127.pub2

21. Sharma R, Sharma V. Effect of magnesium sulphate versus phenytoin on the hospital length of stay of patients of eclampsia and severe preeclampsia. Journal of Chemical and Pharmaceutical Research 2012;4(4):1921-1924. Available at http://jocpr.com/vol4-iss4-2012/JCPR-2012-4-4-1921-1924.pdf

22. MCHIP. Report of second technical working group meeting on pre-eclampsia/eclampsia. Washington, DC.2009.

23. Coalition RHs. Product Brief Caucus on New and Underused Reproductive Health Technologies 2012.

24. Engender Health. A Report on Barriers and Solutions to Treat Pre-eclampsia \& Eclampsia 2007

25. Ugwu EO, Dim CC, Okonkwo CD, Nwankwo TO. Maternal and perinatal outcome of severe pre-eclampsia in Enugu Nigeria after introduction of Magnesium sulfate. Niger J Clin Pract. 2011;14(4):418-421. doi: 10.4103/1119-3077.91747 